\title{
Research on the Implementation of "Separation of Management, Operation and Assessment” Policy in China
}

\author{
Hanwen Zhang \\ School of Education \\ Northeast Normal University \\ Changchun, China
}

\begin{abstract}
Separation of management, operation and assessment" is a significant policy put forward by the Chinese government and it is also a basic component of achieving modern education governance in China. However, the implementation process is confronted with many difficulties because of lacking guidance and experiences. To solve the existed problems, the research is conducted to analyze its deep implication, historical development, current opportunities and challenges. Through literature review, investigation and comparison, some effective suggestions are provided to push forward the policy. It is concluded that the government should manage in a macro and indirect way; schools should stimulate their operation vitality on the autonomy status and social organizations should participate in the assessment activity on the premise of fairness as well as openness.
\end{abstract}

Keywords—policy; definition; opportunity; challenge; strategy

\section{INTRODUCTION}

"Separation of management, operation and assessment" policy is an important link of education reform which first appears in the document of "Decision of Central Committee of Chinese Communist Party on Comprehensively Deepening the Reform of Several Major Issues" and the policy has undergone several stages historically until the current formation. Some obstacles raise during the implementation process and the effect of the policy is greatly damaged. Therefore, it is of far-reaching significance to conduct in-depth research on how to realize the policy's original intention and to achieve the government's "moderate management", the schools' "independent operation", and the society's "scientific assessment".

\section{BODY OF KNOWLEDGE}

A. Overview of "Separation of Management, Operation and Assessment" Policy

\section{1) Academic Definition}

The system theory holds the perspective that the system is an organic whole composed of several segments in a certain structural form with a special function. Similarly, as three segments of the policy system, management, operation and assessment each has clear assignment and also should cooperate appropriately for the joint purpose.

"Management" means taking charge of and being responsible for. The government should transform its function and concentrate on macro coordination instead of direct control. It is in a fundamental position in the whole policy, because only decentralization in management can provide clear path and enough space for "operation" and "assessment”.

"Operation" means organizing and running. Schools should stabilize its autonomy status to reach self-management and self-development. It is the core of the whole policy, because as teaching subjects, schools are established to impart knowledge and educate people. And their performance has great impact on education quality and national development.

“Assessment" means evaluation and supervision. The government's management and schools' operation should be subject to the test from the society. It is the regulator of the whole policy, because timely assessment is beneficial to standardizing their behaviors and help improving the effectiveness of the system.

"Separation of management, operation and assessment" policy means that under modern legal spirit and national legal framework, the government, schools and the society should respect their respective dominant positions and abide by their respective boundaries of rights and responsibilities. Meanwhile, education service market should be nurtured and social forces should be introduced to participate in education supervision in an orderly manner. Therefore, a sound governance structure of government managing education, schools operating education and society assessing education can be formed. ${ }^{[1]}$

\section{2) Policy Development}

Since the promulgation of "Decision of the Central Committee of Chinese Communist Party on Educational System Reform” in 1985, Chinese education management reform has gone through three stages.

The first stage is a policy exploration which emphasizes "management". The Chinese government launched a reform with the objective of reversing the situation that the educational work could not meet the demands of socialist modernization at that time. Some power was delivered to local governments for developing elementary education and implementing nine-year compulsory education.

The second stage is a policy exploration which is based on 
"management and operation". According to the different types of public institutions and operation manners, three patterns emerged at that period. The first one was "the government manage and organizations operate"; the second one was "the government manage and the society operate" and the third one was "the government manage and schools operate". ${ }^{[2]}$ In February 1993, "Chinese Education Reform and Development Program” was put forward. It clarified that a new education system compatible with economic system, political system and technological system under the socialist market should be established. For social organizations and individuals running schools in accordance with law, the country adopts the policy of active encouragement, strong support, correct guidance and formal management. Thus, the situation that the government controlled all school-running activities was changed.

The third stage is a policy exploration which develops into "management, operation and assessment". In the long past, China's education administration was left behind by other developed countries, because the government had three functions in one. Public schools always passively executed superior education departments' administrative orders. And social assessment agencies were both small in number and low in quality. Guiren Yuan, Minister of Education, pointed out at the 2014 National Education Work Conference that the modernization of education governance system and education governance capability should be promoted. Meanwhile, it was necessary to establish a new relationship focusing on the government, schools as well as the society, and to form an effective system on the basic requirement of separating management, operation and assessment. Therefore, the institutional system formed a new pattern of macro government management, independent school operation and extensive social participation. ${ }^{[3]}$

\section{3) Practical Exploration}

From the central government to local governments, some practical explorations are carried out to push forward the policy.

One is the central government's decentralization. Take the year 2014 as an example and three important documents were issued that year. The first one was "Decision on Canceling and Delegating a Batch of Administrative Examination and Approval Projects", in which the State Council cancelled the examination and approval of national key disciplines that used to belong to Ministry of Education. The second one was "Opinions on Deepening the Reform of Educational Supervision and Transforming Education Management Methods" issued by the State Council's Education Steering Committee. The third one was "Opinion on the Implementation of Deepening the Examination Recruitment System" issued by the State Council. In 2015, Ministry of Education promulgated "Notice on the Confirmation of Pilot Units and Pilot Tasks for Management, Operation and Assessment Policy" and thus the policy moved into substantive development.

Second is that some local regions respond to the call of the Central Committee and take the initiative in practice, such as Fangzi District of Weifang in Shandong Province and Pudong New District of Shanghai. In addition, professional education assessment agencies are entrusted by education administrative departments, education institutions and other units at all levels to carry out relevant assessments, such as Jiangsu Education Assessment Institute, Shanghai Education Assessment Institute and Chongqing Education Assessment Institute. ${ }^{[4]}$

\section{B. Opportunities and Challenges Faced by "Separation of Management, Operation and Assessment" Policy}

\section{1) Opportunities}

The first is the support from the government. For example, "Several Opinions of Ministry of Education on Further Promoting the Separation of Management, Operation and Assessment to Promote the Transformation of Government Functions" at the national level and "Shanghai Education Supervision Regulations" at the local level. These will undoubtedly stimulate the whole society to join in the wave of the reform. Moreover, the policy dividend of "Mass Entrepreneurship and Innovation” has provided institutional guarantee for social forces to participate in education governance, especially for setting up schools and educational assessment agencies. In the process of becoming stronger and more mature, the school-running subjects and assessment agencies will in turn promote the transformation of governments' functions.

The second is the material support from social and economic development. On one hand, the average families have realized the significance of education, and they are willing to devote more on children's education. On the other hand, the introduction of market mechanism has also encouraged social organizations and companies to invest in the education industry for its promising prospects. These help to inject a steady stream of vitality into the sustainable development of schools and third-party assessment agencies.

The third is the technical support of globalization and informatization. The whole world is developing rapidly owing to "Internet +". For management, operation and assessment departments, the Internet's convenience and rapidity can provide platform in terms of information sharing and problem solving. Moreover, for the difficulties encountered during the separation process, elaborate analysis can be conducted on the basis of big data and effective suggestions can be given for tripartite education decision. Thus, the efficiency of their respective work is greatly improved.

\section{2) Challenges}

The first challenge manifests as the resistance from the government and education administrative departments. The former education management system had existed for quite a long period and the policy is a completely new attempt under the socialist market economy with distinct Chinese characteristics. Because of lacking experience and practice, people will be confused when confronted with specific issues, such as degree of authorization or decentralization.

The second challenge manifests as the resistance from schools. In the process of coordinating external separation and internal governance, schools need time to break away from their dependence on education administrative departments, to adapt and trust assessment agencies. Meanwhile, principals and other leaders require a struggling stage for authorization 
and decentralization.

The third challenge manifests as the resistance from social assessment agencies. On one hand, the quantity of third-party assessment agencies organized by social forces is limited, and their evaluation results are inadequate in popularity. On the other hand, social organizations have little effect on supervision and control of government as well as education administrative departments.

The fourth challenge manifests as the resistance from communication and assistance. No reform is completed overnight or alone. It requires efforts from different dimensions. Affected by lack of collective incentive measures and influence of individual heroism, most education administrators, school leaders and assessment agency members are used to taking only their own benefits into consideration and proved to be insufficient in cooperation.

\section{Strategy of Implementing "Separation of Management, Operation and Assessment" Policy}

1) Rights and Responsibilities of Each Subject and Their Relationship Should be Clarified.

It is the basic premier of the policy to determine each subject's rights and responsibilities. There is a division of labor and also cooperation among the three. The government should fully revitalize the market potential, raise education development funds through various means, help to adjust imbalance in educational resources among different regions, provide schools with general guidance and standardize social assessment. Schools should abide by their running objectives, undertake education responsibilities, exert the subjective initiative for further development and receive supervision from social forces. Social organizations should actively engage in the education industry, establish a scientific evaluation system, conduct effective supervision and provide useful reference for the government and schools.

2) The government and education administrative departments shall establish the boundaries of functions.

The new-style government in China emphasizes diversified management subjects and manners. The basic requirement is to distinguish the necessary functions from the unnecessary functions. The necessary functions include: macro regulation and control of education scale, structure and layout; planning of schools' development; formulation of education regulations and policies; standard formation for personnel training in various schools; utilization of public finance to share schools' education expenditures; design of transfer payment means to promote education fairness; and construction of a service system that is conducive to schools' development. ${ }^{[5]}$ The unnecessary functions are those within the scope of the schools' autonomy and the society's responsibility, which include: curriculum design, material compilation, students' enrollment and teachers' recruitment as well as promotion. In short, the government and education administrative departments, as defenders of public interests, should exercise their functions in a scientific manner and within an appropriate scope.
3) Schools' subjective status of “operation" should be enhanced.

Schools shoulder the task of talent training, scientific research, social service, cultural heritage and innovation, as well as international cooperation and exchange. Under the background of the demographic dividend turning to the talent dividend, the role of schools is more important than any other historical period. Therefore, their subjective status must be enhanced to fully play these required roles.

First, schools shall optimize the internal governance structure and stimulate the vitality of running schools. To achieve internal governance, the mechanism of board of directors and board of governors should be further perfected. In addition, schools' status of independent legal person should be clarified to realize the joint governance of university teachers, student parents, employers, alumni and other stakeholders. ${ }^{[6]}$ To stimulate the vitality, schools can fully mobilize the initiative as well as creativity of all individuals and encourage them to give suggestions for the development of schools.

Second, schools shall explore the path of "secondary decentralization”. Principals can further delegate the authority delegated by the government to teachers, students and parents, so that the power can be reasonably realized. The concept of "co-governance" should be taken as the foundation of running schools and the wisdom of the whole society should be utilized to promote the formation of an educational cooperation community. ${ }^{[7]}$ As to the method, incentive and competitive mechanisms should be introduced, and the idea of "competition makes progress" should be transmitted to interested groups so as to promote determination, confidence and patience of all sectors of the community for devotion to education.

4) The scope of assessment subjects should be expanded and corresponding fairness as well as effectiveness should be improved.

Because of the inherent characteristics of Chinese education management system and operation system, educational evaluation has many problems, such as utilitarian purpose, simple process and single subject. As a matter of fact, assessment is not only a form of public participation, but also a kind of supervision, criticism and suggestion. ${ }^{[8]}$

First, market-based competition mechanism should be spread to cultivate emerging education assessment agencies. One of the valuable experiences drawn from Europe and the United States is to focus on absorbing various professional organizations, industrial associations, foundations and other social forces to participate in education quality assurance. And the maximization of education governance is achieved through government's service purchasing. ${ }^{[9]}$ The Third Plenary Session of the 18th CPC Central Committee also called for "promoting the government to purchase services, and all management services should, in principle, introduce competition mechanism and be purchased from the society through contracts and commissions." Therefore, social organizations have vast potential to be engaged in assessment. Furthermore, the public should also be promoted as main 
evaluation subjects.

Second, fairness of assessment process and effectiveness of assessment results should be strengthened. One necessary step is that the Chinese government should first confirm the identity of education intermediary organizations, among which the organizational attributes, the interest orientation of participating in public services, the professionalism and authority of providing services, the credibility and influence of education evaluation services are the priorities for identification. For assessment agencies, they should master scientific schemes and advanced techniques for assessing both the utilization of government's power and the performance of schools' obligations. Moreover, the assessment results should be published timely to provide evidence for government's decision-making, offer guidance for schools' operation and give available information for social supervision.

5) The policy should be pushed forward in joint governance.

"Separation of management, operation and assessment" is not complete separation and adequate cooperation among the three is necessary, because the policy is related to interest adjustment and institutional restructuring.

First, the top-down communication channel should be open. The policy is put forward by the central government and its implementation requires multifaceted efforts. On one hand, schools and the society should conduct respective activities under the guidance of the policy. On the other hand, provincial, municipal, as well as county (district) three-tier governments should align and support one another in their educational functions.

Second, the bottom-up reform exploration should be propelled. According to materialistic dialectics, internal causes lie in the first place and determine the development of things; while external causes lie in the second place and only accelerate or delay the development. Therefore, bottom-up innovation exploration is the fundamental force that condenses the overall transformation. Schools and the society should establish the sense of responsibility; reflect on the correct path for fulfilling their responsibilities, and give feedback timely to adjust the deviant behaviors for the formation of a beneficial circle.

\section{CONCLUSION}

The "separation of management, operation and assessment" policy has its profound theoretical foundation and urgent practical demand. After literature review, investigation and comparison, it is suggested that rights and responsibilities of each subject should be clarified; unnecessary functions should be abandoned by the government; schools' subjective status of "operation" should be confirmed; scope of assessment subjects should be expanded and the policy should be pushed forward in joint governance.

\section{REFERENCES}

[1] Huanan Shi, "Time value and reform direction of 'separation of management, operation and assessment' policy," Journal of National Academy of Education Administration, January 2016. (In Chinese)

[2] Qiang Li, “Reflection on the management and operation reform in social fields,” Chinese Cadres Tribune, March 2009,pp. 37-38. (In Chinese)

[3] Guiren Yuan, “Deepen comprehensive education reform and speed up the modernization of education governance and education capability," Chinese Education Paper, February 2014. (In Chinese)

[4] Bing Gao, Xiaomin Yang, Hong Lei, "Nature exploration and implementation path of "separation of management, operation and assessment’ policy,” Education Comment, March 2015. (In Chinese)

[5] Yan Liu, Hanxue Li, "Analysis of reform path of separation, operation and assessment reform in Chinese education governance,” Tianjin Normal University Paper (Basic Education), July 2015. (In Chinese)

[6] Jiale Yang, "Practical exploration of 'separation of management, operation and assessment’ policy,” Yangzhou University Paper (High Education), October 2017. (In Chinese)

[7] Hongqi Chu, "Education governance: better governance on the bas is of co-governance,” Education Research, October 2014, pp. 4-11. (In Chinese)

[8] Zhigang Yang, "Practical exploration and theoretical analysis of 'separation of management, operation and assessment' policy in elementary education field," Journal of The Chinese Society of Education, July 2014. (In Chinese)

[9] Huanan Shi, “Analysis of condition, purpose and strategy of 'separation of management, operation and assessment' policy," Journal of The Chinese Society of Education, July 2015. (In Chinese) 